\title{
ANALISIS PERILAKU PENGENDARA DAN JARAK PANDANG HENTI SEPEDA MOTOR MATIC
}

\section{Analysis of Rider Behavior and Stopping Sight Distance on Matic Motorcycles}

\author{
Erika Buchari \\ Jurusan Teknik Sipil, Fakultas Teknik \\ Universitas Sriwijaya \\ Jl. Raya Prabumulih KM. 32 Indralaya \\ Palembang, Sumatera Selatan \\ eribas17@gmail.com
}

\author{
Ahmad Gilang Dwi Junanta \\ Jurusan Teknik Sipil, Fakultas Teknik \\ Universitas Sriwijaya \\ J1. Raya Prabumulih KM. 32 Indralaya \\ Palembang, Sumatera Selatan
}

\begin{abstract}
The growth of Matic-Motorcycle in Indonesia is increased steeply lately. According to Assosiasion of Indonesian Motorcycle Industry, AISI the sales of matic motorcycle have achieved $75,49 \%(3,639,000)$ of the wholesaler $4,821,000$. In fact, motorcycle users do not realize that automatic motorcycle's characteristics especially braking distance are different with those of non automatic motorcycles. The different way of riding can cause uncontrolled vehicles during braking, when promptly change speed either faster or slower. Stopping sight distance is the distance needed by riders in order to stop their moving vehicles after seeing the obstacles in the front. This research is seeking to know the behavior of motorcycle users and stopping sight distance that is ideal for the users of automatic motorcycles. Multi linear Regression model is made to find out the relationship between stopping sight distance and other variables such as speed, machine capacity, type of brakes etc. From this model, it can be derived the ideal stopping sight distance which is affected by speed, machine capacity, type of front brakes.
\end{abstract}

Keywords: Automatic motorcycles, Stopping sight distance, braking distance

\begin{abstract}
Abstrak
Perkembangan sepeda motor matic di Indonesia mengalami pertumbuhan yang sangat pesat beberapa tahun belakangan ini. Menurut data dari asosiasi industri sepeda motor Indonesia( AISI,2015) penjualan sepeda motor matic mengalami pertumbuhan yang sangat pesat dibandingkan dan motor bebek dan sport, yaitu 75,49\% (3,639 juta matic dari penjualan 4,821 juta motor keseluruhan). Fakta di lapangan, pengguna tidak menyadari beda karakteristik kendaraan motor matic dengan non matic. Perbedaan ini mengakibatkan tidak terkontrolnya kecepatan kendaraan dimana seringnya terjadi perubahan percepatan dan perlambatan pada kendaraan tersebut. Jarak pandangan henti adalah jarak yang dibutuhkan oleh pengendara untuk menghentikan kendaraannya yang bergerak setelah melihat adanya rintangan pada lajur jalannya. Penelitian ini ingin mengetahui perilaku pengendara dan jarak pandang henti yang ideal bagi pengendara sepeda motor matic. Model Multi linear Regression hubungan Jarak pandangan henti dengan variable kecepatan, kapasitas mesin dan jenis rem diteliti. Hasilnya diperoleh jarak henti ideal yang dipengaruhi oleh kecepatan, kapasitas mesin, dan jenis rem depan.
\end{abstract}

Kata kunci : Sepeda motor Matic, Jarak pandang henti, Jarak Pengereman 


\section{PENDAHULUAN}

Masyarakat golongan ekonomi menengah kebawah menganggap bahwa sepeda motor dapat memenuhi segala kebutuhan meraka untuk kegiatan transportasi. Dari Survey Rumah tangga di Palembang 2011, disingkapkan bahwa 43.09\% pengendara motor dan $7.03 \%$ penumpang motor adalah pengguna moda transportasi tunggal motor atau unimodal travelers (E. Buchari, 2011). Alasan paling utama penggunaan motor adalah untuk menghemat waktu perjalanan $43.6 \%$. Selain karena harganya yang murah dan terjangkau, masyarakat banyak menganggap bahwa salah satu alternatif untuk mengatasi kemacetan adalah dengan menggunakan sepeda motor yang memiliki kemampuan dan keunggulan dalam menyalip di sela-sela kemacetan. Akibat kemacetan tersebut banyak pengendara sepeda motor beralih dari menggunakan sistem pengoperasian manual menjadi pengoperasian matic, hal ini di anggap nyaman bagi kebanyakan pengendara.

Sepeda motor matic adalah tipe sepeda motor otomatis yang tidak menggunakan operan gigi manual dan hanya cukup dengan satu akselerasi, sepeda motor ini memiliki kapasitas silinder (CC) kecil dan posisi pengemudi yang tegak, ukuran sepeda motor ini lebih kecil dan ringan daripada tipe bebek. Sepeda motor ini memiliki ruang kosong di antara kemudi dan pengendara yang memungkinkan untuk kaki bisa diletakan di tempat tersebut. Sepeda motor ini sangat cocok untuk wanita dan ini digunakan untuk keperluan dalam kota/wilayah Sepeda motor tipe ini memiliki dimensi ukuran ban dan roda yang cukup kecil. Tapi belakangan ini para pria pun tidak canggung lagi menggunakan sepeda motor tersebut. Tanpa disadari orang menggunakan kakinya untuk mengerem, dan mereka menurunkan kecepatan dengan cara menurunkan kedua kakinya ke perkerasan jalan. Hal ini sangat membahayakan keselamatan pengendara motor tersebut.

Perkembangan sepeda motor matic di Indonesia mengalami pertumbuhan yang sangat pesat beberapa tahun belakangan ini, menurut data dari asosiasi industri sepeda motor Indonesia( AISI,2015) penjualan sepeda motor matic mengalami pertumbuhan yang sangat pesat di bandingkan dan motor bebek dan sport, yaitu $75,49 \%$ (3,639 juta matic dari penjualan 4,821 juta motor keseluruhan) Fakta di lapangan, pengguna tidak menyadari beda karakteristik kendaraan motor matic dengan non matic. Perbedaan ini mengakibatkan tidak terkontrolnya kecepatan kendaraan dimana seringnya terjadi perubahan percepatan dan perlambatan pada kendaraan tersebut. Jarak pandangan henti adalah jarak yang dibutuhkan oleh pengendara untuk menghentikan kendaraannya yang bergerak setelah melihat adanya rintangan pada lajur jalannya.

Oleh sebab itu paper ini dimaksudkan untuk menyingkapkan hubungan penyebab kecelakaan dengan kondisi motor matic dan perilaku pengendara dalam mengatur kecepatannya.

\section{KAJIAN TERDAHULU}

Sudah ada kajian terdahulu yang dilakukan oleh A Ikshan Karim tentang "Analisis Pengaruh Speed humps terhadap karakteristik lalulintas“. Perkembangan teknologi kendaraan bermotor yang semakin pesat menyebabkan kecepatan kendaraan semakin bertambah. Kecepatan kendaraan sebelum di speed humps berbeda dengan kecepatan kendaraan pada saat melintas di speed humps, hal ini menunjukkan bahwa keberadaan speed humps secara nyata mampu untuk menurunkan kecepatan kendaraan. Temuannya 
adalah tentang Hubungan Kecepatan dan Kepadatan diperoleh persamaan linier, sebelum speed humps, yaitu

$$
Y=20,032491-1,1123 X
$$

dengan koeffisien korelasi sebesar 0,958431;

Saat melintas adalah

$$
Y=16,377346-0,718344 X
$$

dengan koeffisien korelasi sebesar 0,98294.

Sedangkan setelah melintas adalah

$$
Y=27,690623-1,643643 X
$$

dengan koeffisien korelasi sebesar 0,991433.

Hubungan Kecepatan dan Aliran lalu lintas mempunyai persamaan sebelum speed humps adalah

$$
f=\frac{20,03249 v-v^{2}}{1,11241}
$$

;saat melintas adalah

$$
f=\frac{16,377346 v-v^{2}}{-0,718344}
$$

sedangkan setelah melintas adalah

$$
f=\frac{27,690623 v-v^{2}}{-1,643643}
$$

Hubungan Kepadatan dan Aliran lalu lintas mempunyai persamaan sebelum speed humps adalah

$$
f=20,03249 d-1,1123 d^{2}
$$

saat melintas adalah

$$
f=16,377346 d-0,718344 d^{2}
$$

sedangkan setelah melintas adalah

$$
f=27,690623 d-1,643643 d^{2}
$$

\section{METODOLOGI PENELITIAN}

Penelitian dilakukan dengan langkah langkah sebagaimana diuraikan pada bagan alir pada gambar 1 berikut ini. 


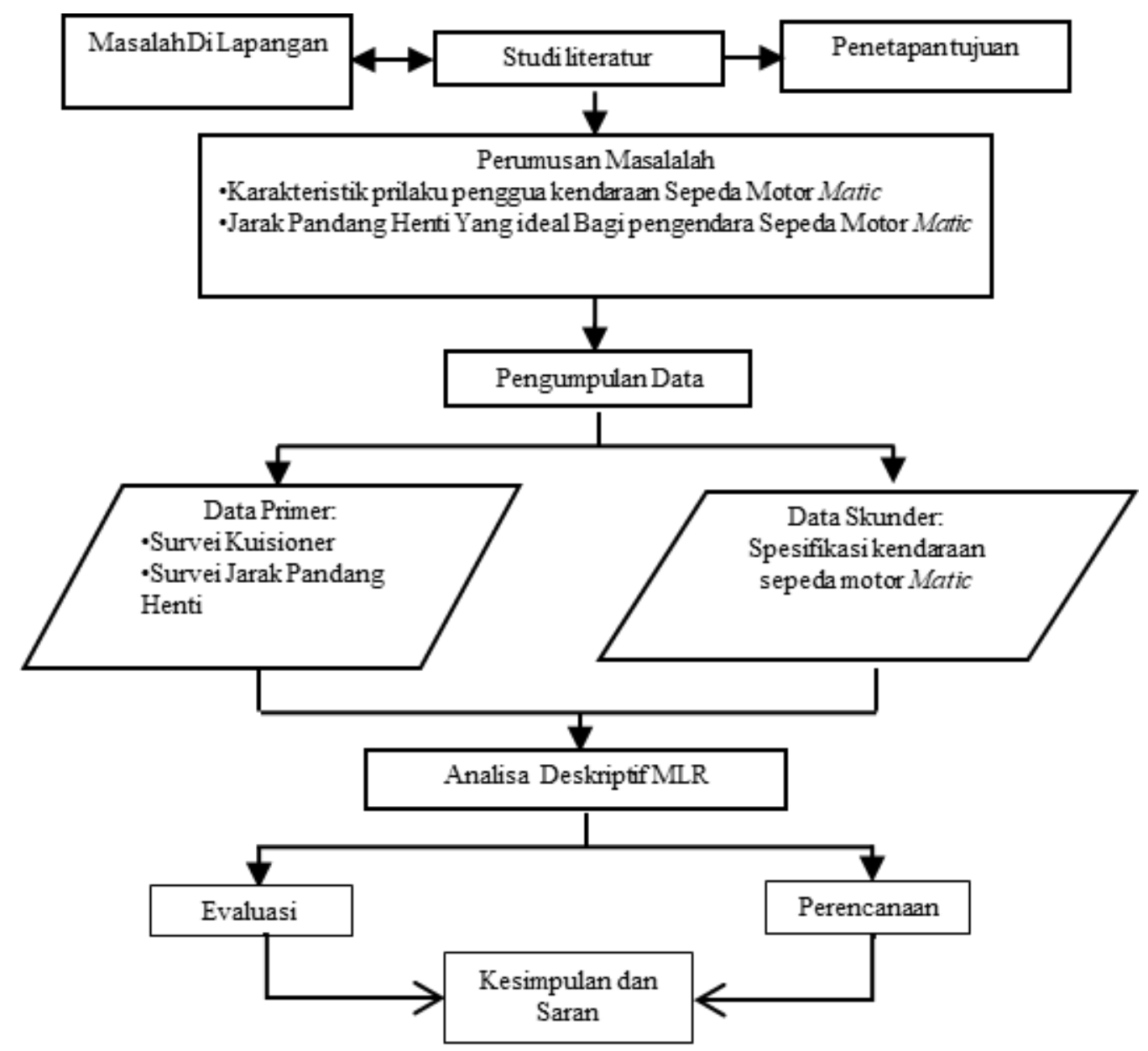

Gambar 1. Bagan alir penelitian

Data primer didapatkan dengan cara observasi atau pengamatan langsung di lokasi penelitian. Pada penelitian ini data primer didapatkan secara langsung di diruas jalan H.M. Noerdin Pandji. Data primer didapatkan dengan cara:

1. Menghitung jarak henti sepeda motor matic dari 10 merk kendaraan dengan menggunakan meteran, dengan berbagai kecepatan yang di pakai sebagai acuan kecepatan, adapun kecepatan yang digunakan antara lain $20 \mathrm{~km} / \mathrm{jam}, 30 \mathrm{~km} / \mathrm{jam}, 40$ $\mathrm{km} / \mathrm{jam}, 50 \mathrm{~km} / \mathrm{jam}, 60 \mathrm{~km} / \mathrm{jam}, 70 \mathrm{~km} / \mathrm{jam}$, dan $80 \mathrm{~km} / \mathrm{jam}$.

2. Penyebaran kuisioner guna mengetahui prilaku pengendara sepeda motot matic di Palembang. Sasaran dari penyebaran kuisioner adalah para pengguna kendaraan sepeda motor matic yang ada diparkiran Palembang Square dan juga pengendara dilingkungan parkiran Fakultas Teknik Universitas Sriwijaya.

Untuk pemodelan Jarak Pengereman Y variable yang diduga berpengaruh adalah

$$
Y=A X_{1}+B X_{2}+C X_{3}+C
$$

Dimana: $Y$ : Jarak pengereman

$\mathrm{X}_{1}$ : Kecepatan

$\mathrm{X}_{2}$ : Kapasitas mesin

$\mathrm{X}_{3}$ : Jenis rem depan

C : Konstanta 


\section{HASIL DAN PEMBAHASAN}

\section{Jarak Pengereman Motor Matic}

Jarak Pengereman Motor Matic dari beberapa kecepatan disajikan pada Tabel 1. berikut ini.

Tabel 1. Data jarak pengereman kedaraan sepeda motor matic

\begin{tabular}{|c|c|c|c|c|c|c|c|c|c|c|c|}
\hline \multirow{2}{*}{$\begin{array}{c}\text { Jenis } \\
\text { Kendaraan }\end{array}$} & \multicolumn{4}{|c|}{ Karakteristik Kendaraan } & \multicolumn{7}{|c|}{ Kecepatan (km/jam) } \\
\hline & $\mathrm{CC}$ & $\begin{array}{c}\text { Rem } \\
\text { Depan }\end{array}$ & $\begin{array}{c}\text { Rem } \\
\text { Belakang }\end{array}$ & $\begin{array}{l}\text { Bobot } \\
\text { Motor }\end{array}$ & 20 & 30 & 40 & 50 & 60 & 70 & 80 \\
\hline Mio J & 110 & 2 & 1 & 92 & 3 & 3,5 & 6 & 8 & 16 & 20 & 25,6 \\
\hline $\begin{array}{l}\text { Mio Soul } \\
\text { GT }\end{array}$ & 125 & 2 & 1 & 96 & 3,5 & 7,6 & 10 & 15,6 & 18,6 & 21 & 29,5 \\
\hline X-Ride & 115 & 2 & 1 & 98 & 2,5 & 2,8 & 7,5 & 8,1 & 13 & 18 & 24,5 \\
\hline Beat & 110 & 2 & 1 & 93 & 2,4 & 6,9 & 7,1 & 11,9 & 16,5 & 19 & 26 \\
\hline New Vario & 125 & 2 & 1 & 112 & 3,2 & 7,8 & 11 & 15,8 & 19 & 21 & 30,1 \\
\hline Scopy & 110 & 2 & 1 & 96 & 2,5 & 6,5 & 6,7 & 12,1 & 15,8 & 17,5 & 25,5 \\
\hline Xeon & 125 & 2 & 1 & 92 & 3,3 & 7,5 & 9,9 & 15,5 & 18,5 & 17 & 29,1 \\
\hline New Vario & 150 & 2 & 1 & 109 & 3 & 8 & 10,2 & 16,9 & 19,5 & 16,5 & 31 \\
\hline Spacy & 125 & 2 & 1 & 96 & 3,5 & 7 & 8 & 11 & 15 & 22,5 & 25 \\
\hline N-Max & 150 & 3 & 3 & 127 & 3 & 5 & 7 & 13 & 15 & 21,5 & 28 \\
\hline
\end{tabular}

\section{HASIL ANALISA DATA}

\section{Uji Normalitas}

Uji normalitas biasanya digunakan untuk mengetahui normal atau tidaknya distribusi dari data yang dipakai dalam variabel tersebut. Uji normalitas merupakan salah satu bagian dari uji asumsi klasik yang harus terpenuhi pada saat pengujian.

\section{Uji Normalitas Smirnov-Kolmogorov}

Dari Uji normalitas Smirnov-Kolmogorov didapatkan hasil besaran angka signifikansi sebesar 0,293, lebih besar dari syarat signifikansi 0,05. Maka dari itu dapat disimpulkan bahwa data memiliki distribusi yang normal.

\section{Uji Linearitas Metode Ramsey}

Dari Uji Linearitas Ramsey ini digunakan untuk mengetahui linear atau tidaknya hubungan antara variabel $\mathrm{X}$ terhadap variabel $\mathrm{Y}$, didapatkan hasil, didapat angka 5.63 pada kolom df. Setelah dilakukan pembacaan nilai $\mathrm{F}$ untuk $\mathrm{F}_{\text {Tabel }}$, didapat angka 2,36. Pada tabel diatas, didapat pula pembacaan $\mathrm{F}_{\text {Hitung }}$ sebesar 0,230. Maka dapat disimpulkan variabel yang akan dimodelkan mempunyai hubungan yang linier, karena $0,230<2,36\left(\mathrm{~F}_{\text {Hitung }}<\right.$ $\mathrm{F}_{\text {Tabel }}$ ). Untuk pembacaan nilai signifikansi, didapat angka 0,948 , maka dapat disimpulkan 
variabel yang akan dimodelkan memiliki hubungan yang linier, karena nilai signifikansi lebih besar daripada $0,05(0,948>0,05)$ untuk taraf kepercayaan $95 \%$.

\section{Uji Multi-Kolinearitas}

Dari Hasil Uji Multi-Kolinearitas dilakukan untuk mengetahui ada tidaknya korelasi antara masing masing variabel bebas di dalam suatu model untuk masing masing variabel bebas, didapat nilai Tolerance sebesar 1,000, 0,379, 0,361, dan 0,214. Maka dari hasil ini dapat disimpulkan bahwa tidak terjadi multi-kolinearitas antara masing-masing variabel bebas dalam model regresi tersebut karena seluruh nilai Tolerance lebih besar dari 0,10 (Tolerance >0,10). Untuk masing-masing nilai Variance Inflation Factor (VIF) didapat masing- masing nilai sebesar 1.000, 2.640, 2.769 dan 4.669, maka dari hasil ini dapat disimpulkan tidak terjadi multi-kolinearitas antara masing-masing variabel bebas dalam model tersebut karena seluruh nilai Variance Inflation Factor (VIF) lebih kecil daripada $10,0(\mathrm{VIF}<10,0)$.

\section{Uji Heteroskedastisitas Metode Glejser}

Dari Uji Heterokedastisitas didapat pembacaan $\mathrm{T}_{\text {hitung }}$ sebesar -0.478 menurut tabel $\mathrm{T}$, untuk jumlah sampel (n) 70 buah dan t 0.05, maka nilai $\mathrm{T}_{\text {tabel }}$ sebesar 1.666. Maka dari itu dapat disimpulkan bahwa tidak terjadi masalah heteroskedastisitas karena $\mathrm{T}_{\text {Hitung }}$ lebih kecil daripada $\mathrm{T}_{\text {Tabel }}(-0.478<1.666)$.

\section{Uji Autokorelasi Metode Durbin-Watson}

Dari Uji Autokorelasi Berdasarkan hasil pembacaan nilai Du dan DL dari tabel DurbinWatson, didapat nilai Du sebesar 1,758, sedangkan nilai DL sebesar 1,4537 (jumlah pengambilan data sebanyak $70 \mathrm{kali}$ dan model mengandung 5 variabel bebas). Maka dari itu, dapat disimpulkan bahwa model regresi terbebas dari gejala Autokorelasi karena koefisien D sebesar 1,412 memenuhi syarat $\mathrm{Du}>\mathrm{D}>(4-\mathrm{Du})$

\section{Koefisien Regresi Model}

Setelah dilakukan analisa terhadap tiap-tiap variabel, akan muncul koefisien pada variabel bebas. Koefisien tersebut merupakan besaran pengaruh dari perubahan nilai pada variabel bebas terhadap variabel terikat. Terjadi perubahan besar koefisien setiap kali terjadi pengeluaran variabel dari model.

Tabel 2. Koefisien persamaan regresi

\begin{tabular}{|c|c|c|c|c|c|}
\hline \multirow[t]{3}{*}{ Coefficients ${ }^{\mathrm{a}}$} & & & & & \\
\hline & \multicolumn{2}{|c|}{$\begin{array}{l}\text { Unstandardized } \\
\text { Coefficients }\end{array}$} & \multirow{2}{*}{$\begin{array}{c}\begin{array}{c}\text { Standardized } \\
\text { Coefficients }\end{array} \\
\text { Beta }\end{array}$} & \multirow[t]{2}{*}{$\mathbf{t}$} & \multirow[t]{2}{*}{ Sig. } \\
\hline & B & Std. Error & & & \\
\hline (Constant) & -11.165 & 2.549 & & -4.380 & .000 \\
\hline speed & .386 & .014 & .954 & 28.499 & .000 \\
\hline $\mathrm{cc}$ & .089 & .024 & .156 & 3.740 & .000 \\
\hline rem_depan & -2.737 & 1.125 & -.102 & -2.433 & .000 \\
\hline
\end{tabular}


Berdasarkan data diatas dapat dibuat persamaan

$$
Y=-11,165+0,386 \text { speed }+0,089 c c-2,737 \text { rem_depan }
$$

Variabel bebas speed, cc, rem_depan memiliki pengaruh yang signifikan di karenakan memiliki nilai signifikan $<0,05$ yang membuat variabel tersebut dapat masuk kedalam persamaan dan menjadi pilihan model untuk mengetahui jarak henti kendaraan sepeda motor matic di kota Palembang. Nilai konstanta yang didapat ialah $-11,165$ meter, nilai yang kurang bagus seharusnya nilainya mendekati nol.

Koefisien speed yang bernilai 0,386 menyatakan pertambahan jarak henti sebesar nilai tersebut jika nilai kecepatan bertambah juga. Koefisien cc sebesar 0,089 menyatakan pertambahan jarak sebesar nilai tersebut jika kapasitas mesin lebih besar. Koefisien rem_depan sebesar - 2,737 menyatakan pengurangan jarak henti sesuai dengan jenis rem yang di pakai, dari persamaan tersebut dapat disimpulkan bahwa jarak henti setelah pengereman di pengaruhi oleh pertambahan kecepatan, besarnya kapasitas mesin motor, dan jenis rem depan, semakin bagus jenis rem depan maka jarak henti yang di hasilkan semakin kecil.

\section{Kalibrasi hasil SPSS untuk jarak Pengereman}

Setelah dilakukan permodel diprogram SPSS didapatkan model atau hasil yang digunakan untuk mengetahui jarak pengereman . Selanjutnya dilakukan kalibrasi dari hasil SPSS tersebut. Adapun bentuk permodelan yang didapat dari program SPSS adalah Sebagai Berikut :

$$
Y=-11,165+0,386 X_{1}+0,089 X_{2}-2,737 X_{3}
$$

Dimana: $\mathrm{Y}$ : Jarak pengereman

$\mathrm{X}_{1}$ : Kecepatan

$\mathrm{X}_{2}$ : Kapasitas mesin

$\mathrm{X}_{3}$ : Jenis rem depan

Setelah didapatkan persamaan, maka dimasukanlah nilai rata - rata yang didapatkan dari hasil Descriptive statistics kedalam variabel persamaan yang didapat. Adapun rata - rata variabel yang didapatkan dari hasil Descriptive statistics adalah sebagai berikut :

Dari data tabel diatas dimasukan kedalam persamaan sebagai berikut :

$$
\begin{aligned}
& Y=-11,165+0,386(50)+0,089(124,5)-2,737(2,1) \\
& Y=-11,165+19,3+11,085-5,7477 \\
& Y=13,4678
\end{aligned}
$$

Jadi dengan kecepatan $50 \mathrm{~km} / \mathrm{jam}$, dengan kapasitas mesin sebesar 124,5 cc dan dengan mengunakan tipe rem 2 ( tipe rem cakram ) maka didapatkan jarak pengereman kendaraan sepeda motor tersebut sebesar $13,4678 \mathrm{~m}$

\section{KESIMPULAN}

Hasil dari Permodelan yang di dapat berupa jarak henti yaitu

$$
Y=-11,165+0,386 \text { speed }+0,089 c c-2,737 \text { rem_depan }
$$


Variabel bebas speed, cc, rem_depan memiliki pengaruh yang signifikan di karenakan memiliki nilai signifikan $<0,05$ yang membuat variabel tersebut dapat masuk kedalam persamaan dan menjadi pilihan model untuk mengetahui jarak henti kendaraan sepeda motor matic di kota Palembang. Nilai konstanta yang didapat ialah nilai yang dimana jika dilakukan pengereman jarak henti kendaraan akan berkurang sebesar 11,165 meter. Koefisien speed yang bernilai 0,386 menyatakan pertambahan jarak henti sebesar nilai tersebut jika nilai kecepatan bertambah juga. Koefisien cc sebesar 0,089 menyatakan pertambahan jarak sebesar nilai tersebut jika kapasitas mesin lebih besar. Koefisien rem_depan sebesar - 2,737 menyatakan pengurangan jarak henti. Jadi untuk menghitung jarak henti kendaraan sepeda motor matic ialah dengan memasukan berapa kecepatan kendaraan, berapa kapasitas mesin kendaraan, dan jenis rem apa yang digunakan oleh pengendara tersebut.

\section{Saran}

Dari kesimpulan diatas, maka dapat dikemukan beberapa saran yang bermanfaat untuk penelitian berikut nya yaitu

1. Penelitian ini hanya mengambil 10 sampel kendaraan sepeda motor matic, diharapkan untuk penelitian selanjutnya dapat menambahkan sampel kendaraan yang lebih banyak sehingga mempunyai model yang lebih sempurna.

2. Dapat di gunakan metode lain untuk menghitung jarak henti kendaraan sepeda motor matic.

3. Dari hasil penelitian tersebut semoga dapat digunakan untuk menentuk jarak pengereman yang ideal bagi penguna kendaraan sepeda motor matic yang semakin banyak.

\section{DAFTAR PUSTAKA}

Guntur, Muhammad. 2013. Studi Prilaku Pengendaran Sepeda Motor Di Kota Makasar. Makasar

Nurmianti, Darni. 2015. Analisis Prilaku Menyiap Kendaraan Sepeda Motor Pada Ruas Jalan Arteri Di Kota Makasar.Makasar

Karyawan,Widianty, 2014. Analisis Jarak Pandang Henti Sebagai Elemen Geometrik Pada Beberapa Tikungan Pada Ruas Jalan Mataram- Lembar

Rizkiansah, Anna, 2012. Analisis Tingkah Laku Pengendara Sepeda Motor di Kota Surabaya Dengan driver behavior questionnaire(DBQ)".Surabaya 